This item was submitted to Loughborough's Research Repository by the author.

Items in Figshare are protected by copyright, with all rights reserved, unless otherwise indicated.

\title{
Greater toe grip and gentler heel strike are the strategies to adapt to slippery surface
}

\section{PLEASE CITE THE PUBLISHED VERSION}

http://dx.doi.org/10.1016/j.jbiomech.2007.11.001

\section{PUBLISHER}

(C) Elsevier

\section{VERSION}

AM (Accepted Manuscript)

\section{PUBLISHER STATEMENT}

This work is made available according to the conditions of the Creative Commons Attribution-NonCommercialNoDerivatives 4.0 International (CC BY-NC-ND 4.0) licence. Full details of this licence are available at: https://creativecommons.org/licenses/by-nc-nd/4.0/

\section{LICENCE}

CC BY-NC-ND 4.0

\section{REPOSITORY RECORD}

Fong, Daniel Tik-Pui, De-Wei Mao, Jing-Xian Li, and Youlian Hong. 2019. "Greater Toe Grip and Gentler Heel Strike Are the Strategies to Adapt to Slippery Surface”. figshare. https://hdl.handle.net/2134/21169. 


\section{Elsevier Editorial System(tm) for Journal of Biomechanics Manuscript Draft}

Manuscript Number: BM-D-07-00298R2

Title: Greater toe grip and gentler heel strike are the strategies to adapt to slippery surface

Article Type: Full Length Article (max 3000 words)

Section/Category:

Keywords: Slips and falls, injury prevention, plantar pressure

Corresponding Author: Dr. Youlian Hong,

Corresponding Author's Institution: The Chinese University of Hong Kong

First Author: Daniel Tik-Pui Fong, MSc

Order of Authors: Daniel Tik-Pui Fong, MSc; De-Wei Mao, PhD; Jing-Xian Li, PhD; Youlian Hong, PhD Manuscript Region of Origin: 


\section{Conflict of interest}

Dear Editor of Journal of Biomechanics,

REF: Submission of manuscript titled "Prolonged toe grip and gentler heel strike are the strategies to adapt to slippery surface".

We declare no financial and personal relationships with other people or organizations that could inappropriately influence this submitted work.

Daniel Tik-Pui FONG,

De-Wei MAO,

Jing-Xian LI,

Youlian HONG

May 3rd, 2007. 


\section{Cover Letter}

Dear Editor of Journal of Biomechanics,

\section{REF: Submission of manuscript titled "Prolonged toe grip and gentler heel strike are the strategies to adapt to slippery surface".}

We would like to submit the mentioned manuscript as an Original Article to Journal of Biomechanics. Each author has been involved in the design of the study, interpretation of the data, and writing of the manuscript and that each of the authors has read and concurs with the content in the manuscript. The material within has not been and will not be submitted for publication elsewhere except as an abstract. We do not recommend any reviewers and would like to leave the decision to the editors.

Daniel Tik-Pui FONG,

De-Wei MAO,

Jing-Xian LI,

Youlian HONG

May 3rd, 2007. 


\begin{tabular}{|c|c|c|c|}
\hline Article Title & \multicolumn{3}{|c|}{$\begin{array}{l}\text { Greater toe grip and gentler heel strike are the strategies to adapt } \\
\text { to slippery surface }\end{array}$} \\
\hline Authors & \multicolumn{3}{|c|}{$\begin{array}{l}\text { Daniel Tik-Pui } \text { FONG }^{1,2} \text {, De-Wei } \text { MAO }^{1,3} \text {, Jing-Xian } \text { LI }^{1,4} \text {, } \\
\text { Youlian } \text { HONG }^{1}\end{array}$} \\
\hline Affiliations & \multicolumn{3}{|c|}{$\begin{array}{l}{ }^{1} \text { Department of Sports Science and Physical Education, Faculty of } \\
\text { Education, The Chinese University of Hong Kong, Shatin, Hong } \\
\text { Kong, China. } \\
{ }^{2} \text { Department of Orthopaedics and Traumatology, Prince of Wales } \\
\text { Hospital, Faculty of Medicine, The Chinese University of Hong } \\
\text { Kong, Shatin, Hong Kong, China. } \\
{ }^{3} \text { Shandong Institute of Physical Education and Sports, Jinan, } \\
\text { Shandong, China. } \\
{ }^{4} \text { School of Human Kinetics, Faculty of Health Sciences, } \\
\text { University of Ottawa, Ontario, Canada. }\end{array}$} \\
\hline Address & \multicolumn{3}{|c|}{$\begin{array}{l}\text { Human Movement Laboratory, } 101 \text { Kwok Sports Building, The } \\
\text { Chinese University of Hong Kong, Shatin, Hong Kong, China }\end{array}$} \\
\hline \multicolumn{4}{|c|}{ Correspondence author during review process: Daniel Tik-Pui FONG } \\
\hline Telephone & (852) 26096079 & Facsimile & (852) 26035781 \\
\hline E-mail & \multicolumn{3}{|c|}{ dfong@ort.cuhk.edu.hk / dfong@alumni.cuhk.edu.hk } \\
\hline \multicolumn{4}{|c|}{ Correspondence author if paper is accepted: Youlian HONG } \\
\hline Telephone & $(852) 26096082$ & Facsimile & $(852) 26035781$ \\
\hline E-mail & \multicolumn{3}{|c|}{ youlianhong@cuhk.edu.hk } \\
\hline Total words & 3179 & Words in abstract & 239 \\
\hline Keywords & \multicolumn{3}{|c|}{ Slips and falls, injury prevention, plantar pressure. } \\
\hline
\end{tabular}




\section{ABSTRACT}

2 This study investigated the plantar pressure distribution during gait on wooden surface

3 with different slipperiness in the presence of contaminants. Fifteen Chinese males

4 performed ten walking trials on a 5-meter wooden walkway wearing cloth shoe in

5 four contaminated conditions (dry, sand, water, oil). A pressure insole system was

6 employed to record the plantar pressure data at $50 \mathrm{~Hz}$. Peak pressure and

7 time-normalized pressure-time integral were evaluated in nine regions. In comparing

8 walking on slippery to non-slippery surfaces, results showed a $30 \%$ increase of peak

9 pressure beneath the hallux (from 195.6 to $254.1 \mathrm{kPa}$ ), with a dramatic $79 \%$ increase

10 in the pressure time integral beneath the hallux (from 63.8 to $114.3 \mathrm{kPa}$ ) and a $34 \%$

11 increase beneath the lateral toes (from 35.1 to $47.2 \mathrm{kPa}$ ). In addition, the peak

12 pressure beneath the medial and lateral heel showed significant $20-24 \%$ reductions

13 respectively (from $233.6-253.5$ to $204.0-219.0 \mathrm{kPa}$ ). These findings suggested that

14 greater toe grip and gentler heel strike are the strategies to adapt to slippery surface.

15 Such strategies plantarflexed the ankle and the metatarsals to achieve a flat foot

16 contact with the ground, especially at heel strike, in order to shift the ground reaction

17 force to a more vertical direction. As the vertical ground reaction force component

18 increased, the available ground friction increased and the floor became less slippery.

19 Therefore, human could walk without slip on slippery surfaces with greater toe grip 
20 and gentler heel strike as adaptation strategies.

\section{INTRODUCTION}

23 Twenty years ago, slips and falls made people laugh rather than implemented

24 preventive measures (Saari, 1990). This was due to a lack of serious public concern

25 and the common belief that these were just unfortunate or normal accidents (Leamon

26 and Murphy, 1995). In recent decade, public awareness has aroused, as slips and falls

27 caused obvious undesired outcomes, including fracture, disability, financial lost,

28 medical expenditure, and deaths (Courtney and Webster, 1999). Even if a slip does not

29 result in a fall, muscular strain or back pain are often induced from recovery

30 corrective actions (Manning and Shannon, 1981). Redfern et al (2001) suggested that

31 slip events are caused by multiple, interacting environmental and human factors.

32 When the extrinsic environmental factors introduced a potential slippery surface

33 which could be anticipated, i.e., an icy and snowy surface (Gao and Abeysekera,

34 2004), human could evoke changes in intrinsic factors, i.e., gait patterns (Cham and

35 Redfern, 2002), in order to reduce the slip probability. Failure to appropriately change

36 the intrinsic human factors to adapt the extrinsic environmental factors may lead to a

37 slip, and eventually a fall. 
39 Figure 1 shows a theoretical framework for the understanding of gait adaptation to

40 prevent slip. In walking on level surface, human require certain amount of ground

41 friction to propagate. When the ground friction is enough, ie., when the surface is dry

42 or non-slippery, the available friction is greater than the required friction. Therefore,

43 the ground could accommodate the demand of the human gait, and there is a low

44 chance of slip. When the ground friction is not enough - the available friction is less

45 than the required friction, a slip may occur if one keeps walking without any changes

46 in gait. However, human could adapt by lowering the required friction, or increasing

47 the available friction, in order to walk without slip. Such adaptation could be

48 demonstrated by kinematics, kinetics and myoelectric changes to quantify how human

49 "walk carefully" on slippery surfaces.

51 The human foot is the direct contact between the body and the external environment.

52 It supports the body, transmits forces between the body and the ground, adapts to

53 ground surfaces, and acts as a cushion to the remaining body (Chen et al, 1995). It

54 also serves as a system for sensory input to convey information about the magnitude

55 and direction of small strains that occur on the plantar surface, which are crucial to

56 keep balance and avoid falls (Tanaka et al, 1996). The hallux, or the great toe, was

57 suggested to be sensitive to external tactile sense and stimuli. It significantly 
73 Numerous kinematics studies in the research of slips have been published (Brady et al,

74 2000; Cham and Redfern, 2002; Lockhart et al, 2003; Myung and Smith, 1997). In

75 kinetics, most studies investigated the available friction between shoe and surface by a

contributes to the neural feedback to maintain postural stability (Nurse and Nigg, 1999). Human can maintain balance by exerting different toe pressure in order to correct for many postural disturbances, i.e., slips and trips, during locomotion (Tanaka et al, 1996). In preventing slips during gait, human also tend to adopt with a gentler heel strike, in order to reduce the collision-forces in the shoe/surface interface during weight acceptance, a factor important for maximizing friction and slip resistance in watery, oily and snowy surfaces (Gronqvist, 1999). Such gentler heel strike was shown by a flat foot landing at heel strike (Fong et al, 2005). The body's center of mass moves forward, so the shoe/floor contact area appears to increase to achieve lower shear forces (Gard and Berggard, 2006). Further kinematics study showed a decrease in horizontal heel velocity, horizontal heel acceleration and vertical heel acceleration at heel strike (Fong et al, 2005). In summary, Gronqvist et al (2001) suggested that the control of foot trajectory to achieve safe ground clearance and gentle heel landing is one critical motor function for safe gait.

\footnotetext{
inetics, most studies investigated the available friction between shoe and surface by a
} mechanical test (Aschan et al, 2005; Redfern and Bidanda, 1994), or compared the 
77 available and utilized friction during a human gait test (Burnfield et al, 2005; Hanson

78 et al, 1999). To date, no studies reported the plantar pressure kinetics when preventing

79 slips in gait. This study aims to investigate the plantar pressure during gait on wooden

80 surfaces with different slipperiness when contaminated with sand, water and oil.

81 Kinematics, myoelectric and joint moment findings were presented elsewhere (Fong

82 et al, 2005; in press) In this study, it is hypothesized that there are differences in

83 plantar pressure distribution during gait on slippery and non-slippery surfaces, or to be

84 specific, there are gentler heel strike and greater toe grip when walking on slippery

85 surfaces.

86

87 METHODS

88 Fifteen Chinese males (age $=21.8 \pm 1.3 \mathrm{yr}$, mass $=64.5 \pm 4.6 \mathrm{~kg}$, height $=1.75 \pm 0.06$

$89 \mathrm{~m}$, foot length $=260-265 \mathrm{~mm}$ ) with no gait abnormalities and with right-leg

90 dominance were recruited for this study. Written informed consent was obtained from

91 all subjects before the study. The university ethics committee approved the study. A

92 harness system was installed to ensure subjects' safety. Each subject wore a pair of

93 cloth shoe of size 42 (length $=265 \mathrm{~mm})$ and walked ten times on a 5-meter walking

94 path made of dry wooden surface. The cloth shoe (Fong et al, 2007) was made with a

95 thin layer of cloth upper and a smooth and flexible rubber sole with no compliance to 
96 any slip resistance enhancement, thus minimizing any compensation to the surface

97 slipperiness introduced by the contaminants. Moreover, with its thin and flexible

98 rubber sole, it allows the foot to better sense the extrinsic slippery environment. After

99 walking on the dry surface, contaminants were added in the sequence of sand, water

100 and oil (elf 10W40 motor oil). The amounts were about $1 \mathrm{~L} / \mathrm{m}^{2}$ for sand and $0.5 \mathrm{~L} / \mathrm{m}^{2}$

101 for water and oil, which could form a full or almost-full coverage on each plate

102 without spilling out. The testing sequence was not randomized, as to prevent

103 cross-contamination on the testing surface (Hanson et al, 1999), and more importantly,

104 to prevent the gait anticipation effect (Cham and Redfern, 2002).

105

106 The available ground friction of each flooring condition, which was quantified as the

107 dynamic coefficient of friction (DCOF), was evaluated by a mechanical

108 slip-resistance test. A self-designed simple pulley system, which allowed an adjustable

109 horizontal drag force, was used to drag a 11.8-kg-weighted shoe over the wooden

110 testing surface mounted on top of a force plate (Kistler 9281CA, Switzerland) (Fong

111 et al, 2005). Contaminants were added on top of the testing surface. Weights were

112 added to increase the horizontal drag gradually until the shoe slid. The DCOF was

113 obtained by the ratio of shear to normal ground reaction force during the slide. Ten

114 trials were conducted for each flooring condition. According to the measured DCOF 
115 and the classification scale suggested by Gronqvist et al (1989), the slipperiness of

116 each condition was classified into very slip resistant, slip resistant, unsure, slippery or 117 very slippery.

119 During each walking trial, subjects were instructed to look forward and walk at a

120 self-paced normal speed and avoid slipping. Before each testing condition, each

121 subject was given enough time (about 2 minutes) to practice in order to achieve

122 successful non-slip gait, in order to demonstrate his strategy to adapt to the walkway

123 conditions. One digital video camera (JVC 9600, Japan) with $100 \mathrm{~Hz}$ filming rate was

124 used for videotaping the human motion in sagittal plane to detect slips. Reflective

125 markers were attached at the heel counters of the shoe for measuring heel horizontal

126 velocity, and at greater trochanter for measuring the walking speed. Video data were

127 processed and analyzed by a motion analysis system (Ariel Performance Analysis

128 Systems, U.S.). A slip was defined as when the subject required support from the

129 harness as reported by the subject, or when the heel horizontal velocity failed to

130 achieve zero within a 3-cm displacement range (Maynard, 2002) immediately after

131 the foot strike, which was checked by motion analysis. Trials with slips were 132 discarded.

133 
134 A pressure insole system (Novel Pedar, Germany) was employed to collect plantar

135 pressure distribution of both feet during each trial. There were 99 sensors in each

136 insole to collect plantar pressure data in $\mathrm{kPa}$ at $50 \mathrm{~Hz}$. All individual sensors were

137 calibrated with a calibration device (Novel Trublu, Germany). The reliability and

138 validity of this device has been well documented (Kernozek et al, 1996; Putti et al,

139 2006; Quesada et al, 1997). The pressure distribution data were evaluated in nine

140 regions which were automatically created by the insole system (Novel Automask,

141 Germany), as shown in Figure 2: (1) hallux, (2) lateral toes, (3) $1^{\text {st }}$ metatarsal head, (4)

$1422^{\text {nd }}$ and $3^{\text {rd }}$ metatarsal heads, (5) $4^{\text {th }}$ and $5^{\text {th }}$ metatarsal heads, (6) medial mid-foot, (7)

143 lateral mid-foot, (8) medial heel, and (9) lateral heel. Peak pressure and

144 time-normalized pressure-time integral of each region during a stance period was

145 evaluated. The stance time was determined when the total ground reaction force

146 beneath the foot was over two Newtons, which was automatically identified by the

147 pressure insole system. Since the stance time differed in each trial as a result of

148 different walking speeds, the pressure-time integral was normalized to the stance time.

149 The time-normalized pressure-time integral represents the average amount of pressure

150 exertion or loading within a stance period (Mao et al, 2006). Pressure data from both

151 feet were evaluated together. As walking speed was expected to influence the plantar

152 pressure, analysis of variance (ANOVA) with Tukey post-hoc pairwise comparisons 
153 was conducted to investigate any significant difference among the four conditions. If

154 significant difference was found, walking speed would be set as a covariant in the

155 statistical analysis for peak pressure. Since the time-normalized pressure-time integral

156 was already normalized to time, speed would not be set as covariant. Repeated

157 measures one-way analysis of covariance/variance (ANCOVA/ANOVA) was

158 employed to examine the difference in each parameter to see the effects introduced by

159 the surface contaminants. Tukey post-hoc pairwise comparisons were conducted

160 between each pair of contaminant condition when significant differences among were

161 shown in ANCOVA/ANOVA. Significance level was set at $\mathrm{p}<0.05$ level.

162

163 RESULTS

164 The four testing conditions had the DCOF value ranging from 0.107 to 1.057 (Table

165 1). The dry and watery conditions were classified as "very slip-resistant" as they had a

166 DCOF value of 0.3 or above. The watery condition had a higher DCOF value (1.057)

167 than the dry condition (0.808). The sand condition was classified as "slip-resistant" as

168 it had a DCOF value of $0.20-0.29$. The oily condition was classified as "slippery" as it

169 had a DCOF value lower than 0.14 but higher than 0.05 . A total of 600 trials were

170 collected during the human walking test. Eighteen trials (3\%) were discarded from the

171 oily condition due to slip occurrence detected by the motion analysis system after data 
172 collection.

173

174 The walking speeds of the four conditions are shown in Figure 3. ANOVA with Tukey

175 post-hoc pairwise comparisons showed that the walking speed in trials with oil

176 contaminant was significantly slower than other three trials $(\mathrm{p}<0.05)$. Therefore,

177 walking speed was set as a covariate in the statistical analysis for peak pressure.

178 Descriptive data and the results of the ANCOVA/ANOVA and the Tukey post hoc

179 pairwise comparisons are shown in Table 2 and Table 3. On oily surfaces, peak

180 pressures beneath the medial and lateral heel decreased significantly $(\mathrm{p}<0.05)$.

181 Significant increase at hallux was also found $(\mathrm{p}<0.05)$. Pressure in the mid-foot areas

182 was comparably low and did not differ across all conditions. For time-normalized

183 pressure-time integral, dramatic increases were found beneath the hallux and lateral

184 toes $(\mathrm{p}<0.05)$, as illustrated in Figure 4.

185

186 DISCUSSION

187 This study investigated the plantar pressure changes during gait on wooden surface

188 with different slipperiness in the presence of sand, water and oil as contaminants. The

189 slipperiness of each condition was represented by the dynamic coefficient of friction

190 (DCOF) measured by a mechanical slip-resistance test. Perkins (1978) suggested that 
191 the most critical moment for slips to happen is within $0.05-0.10$ second after heel

192 contact, as the ratio of horizontal to vertical ground reaction force during this period is

193 extraordinary high, i.e., the demand of shear ground reaction force could easily

194 exceed the available ground reaction force. During this period of time, the vertical

195 ground reaction force is about $10-20 \mathrm{~kg}$. In this study, a load of $11.8 \mathrm{~kg}$ in the shoe

196 was selected for the mechanical slip-resistance test. This represented about $20 \%$ body

197 weight of a male adult (about $60 \mathrm{~kg}$ ).

198

199 On wet surface, it was found that the DCOF value was higher than that of dry

200 condition. Although there is a general consensus that wet surface should be slippery,

201 thus, the DCOF value should be lower, there were also previous studies reporting

202 opposite findings. For instance, Manning and Jones (2001) investigated the surface

203 slipperiness between rubber solings with contaminants and found that some rubbers

204 achieved higher coefficient of friction on wet floors. Newton and coworkers (2002)

205 investigated the friction between wrestling shoes and wrestling mats. They found that

206 for old shoe and old mat which has been used over a season, the coefficient of friction

207 was significantly higher in wet $(0.76)$ than in dry $(0.60)$ condition - the wet condition

208 was less slippery. In this test, the shoe and mat surfaces were already smoothened by a

209 one-season usage. The condition was like that of the current study, with smooth 
210 wooden surface and shoe with smooth rubber sole. The finding was also in agreement

211 with the result of the current study - the DCOF value in wet condition is higher than

212 that of dry condition. The finding also suggests that the flooring surfaces must be

213 tested by mechanical test, and could not be assumed to be more slippery to a dry

214 condition.

215

216 When walking on non-slippery surfaces (i.e., watery, dry and sandy in this study), the

217 peak pressures were higher beneath the heel and metatarsal regions with values of

218 about $200 \mathrm{kPa}$. When walking on slippery surfaces (i.e., oily condition in this study),

219 peak pressures at forefoot tended to shift from metatarsal regions to toes, especially to

220 the hallux which showed a $30 \%$ increase of peak pressure when compared to the dry

221 conditions (from 195.6 to $254.1 \mathrm{kPa}$ ). In addition, there was a dramatic $79 \%$ increase

222 in the pressure exertion beneath the hallux (from 63.8 to $114.3 \mathrm{kPa}$ ), accompanied

223 with a $34 \%$ increase beneath the lateral toes (from 35.1 to $47.2 \mathrm{kPa}$ ), as represented by

224 the time-normalized pressure-time integral values. These findings suggest that

225 metatarsal plantarflexion (Shereff et al, 1986) occurred when walking on slippery

226 surfaces, as shown by a slight reduction of peak pressure beneath the metatarsal head

227 regions (from $176.3-206.0$ to $162.3-183.6 \mathrm{kPa}$ ) and a significant increase of peak

228 pressure beneath the the hallux. Such forefoot motion initiated greater toe grip, which 
229 was shown by the increased pressure exertion at the hallux and lateral toes. The

230 results confirmed part of the hypothesis of this study - there is a greater toe grip to

231 adapt to slippery surface in walking.

232

233 The peak pressure beneath the medial and lateral heel showed significant $20-24 \%$

234 reductions in respectively when walking on slippery surfaces (from 233.6-253.5 to

$235204.0-219.0 \mathrm{kPa}$ ). This suggested a gentler heel strike was performed, and this finding

236 confirmed the remaining part of the hypothesis of this study - there is a gentler heel

237 strike to adapt to slippery surface in walking. This finding is also accompanied with

238 the slight decrease of the pressure exertion at medial heel (5\%, from 80.9 to $76.6 \mathrm{kPa})$

239 and lateral heel $(6 \%$, from 75.9 to $71.2 \mathrm{kPa})$, though such reduction was not

240 statistically significant. However, this finding was in agreement of our previous study

241 which showed a flat foot landing at heel strike, and also a gentler heel strike in

242 walking on slippery surfaces as represented by kinematics data (Fong et al, 2005).

243

244 One limitation in this study was the use of safety harness for protecting the subjects

245 from slips and falls. In attempt to minimize this effect, the harness was adjusted for

246 each subject so that it could prevent the subject hitting the ground and at the same

247 time it would not affect the subject's normal gait as perceived and verbally reported 
248 by the subject. Walking speed was not controlled in this study and the subjects were

249 instructed to walk at a self-paced normal speed that they would do when they walk on

250 such surfaces with different slipperiness as they could sense, in order to reflect the

251 most realistic slip preventive strategies. The variation of walking speed could be

252 demonstrated by the stance duration. Therefore, the effect of variation of walking

253 speed on the measure parameters was minimized by normalizing the pressure-time

254 integral to the stance duration. Moreover, walking speed was treated as a covariant in

255 the statistical analysis to encounter the effect introduced to the peak pressure

256 measurements.

258 The sequence of trials was not randomized, but in order of dry, sand, water and oil.

259 This was to prevent cross-contamination on the testing surface as mentioned by

260 Hanson and coworkers (1999), and more importantly to prevent the gait anticipation

261 effect demonstrated by Cham and Redfern (2002). In their studies, subjects walked on

262 dry surface first, and then on anticipation trial with contaminants, and finally on dry

263 surface again. Even the subjects were told that the final trial was on dry surface and

264 were instructed to walk normally, they still demonstrated significant gait changes as

265 compared with the baseline condition in the first trial on dry surface. Therefore the

266 sequence was assigned in the order in order to minimize such effect. The tests were 
267 carried out in a given order with the dry condition done first, followed by the sand 268 condition. The wet and oily surfaces were believed to be more slippery and were put 269 in the last.

271 This study suggested that the greater toe grip and gentler heel strike would be the 272 strategy to maintain balance in order to adapt to slippery surface and prevent slip. We 273 postulated that these two adaptations together plantarflexed the ankle and the 274 metatarsals to achieve a flat foot contact with the ground, especially at heel strike 275 (Fong et al, 2005). These strategies shift the ground reaction force to a more vertical 276 direction, which is important in reducing the shear force applying to the ground, and 277 also in gaining greater available ground friction for braking purpose. When the 278 vertical component of ground reaction force is greater, the available ground friction 279 increases as it is a function of the vertical ground reaction force. Therefore, the 280 available ground friction becomes more readily available and the floor becomes less 281 slippery if human could achieve flat foot landing as early as possible after heel strike. 282 In addition, Nurse and Nigg (1999) suggested that the tactile sense of the hallux 283 contributes to the balance control. This is also in agreement that elderly people who 284 practice Tai Chi, which involves lots of hallux pressure exertion, could maintain better 285 balance control and fewer slips and falls (Mao et al, 2006). Therefore, somatosensory 
286 training of the activity and the sensation of the hallux could be an intervention to slip

287 prevention. However, footwear may prohibit the sensitivity of the foot to the external

288 environment and stimuli (Nurse and Nigg, 1999), and therefore it is important to

289 include sensory feedback and sensitivity of the foot in shod condition in the future

290 research of slips and falls.

\section{ACKNOWLEDGEMENT}

293 This study was financially supported by the Hong Kong Occupational Safety and 294 Health Council.

\section{REFERENCES}

297 Aschan, C., Hirvonen, M., Mannelin, T., Rajamaki, E., 2005. Development and 298 validation of a novel portable slip simulator. Applied Ergonomics 36, 585-593. 299 Brady, R.A., Pavol, M.J., Owings, T.M., Grabiner, M.D., 2000. Foot displacement but 300 not velocity predicts the outcome of a slip induced in young subjects while $301 \quad$ walking. Journal of Biomechanics 33, 803-808.

302 Burnfield, J.M., Tsai, Y.J., Powers, C.M., 2005. Comparison of utilized coefficient of 303 friction during different walking tasks in persons with and without a disability. $304 \quad$ Gait and Posture 22, 82-88.

305 Cham, R., Redfern, M.S., 2002. Changes in gait when anticipating slippery floors. $306 \quad$ Gait and Posture 15, 159-171.

307 Chen, H., Nigg, B.M., Hulliger, M., de Koning, J., 1995. Influence of sensory input on 
plantar pressure distribution. Clinical Biomechanics 10, 271-274.

309 Courtney, T.K., Webster, B.S., 1999. Disabling occupational morbidity in the United States. An alternative way of seeing the Bureau of Labor statistics' data.

312 Fong, D.T.P., Hong, Y., Li, J.X., 2005. Lower-extremity gait kinematics on slippery surfaces in construction worksites. Medicine and Science in Sports and Exercise 37, 447-454. 
334 Kernozek, T.W., LaMott, E.E., Dancisak, M.J., 1996. Reliability of an in-shoe 335 pressure measurement system during treadmill walking. Foot and Ankle $336 \quad$ International 17, 204-209.

337 Leamon, T.B., Murphy, P.L., 1995. Occupational slips and falls: More than a trivial $338 \quad$ problem. Ergonomics 38, 487-498.

339 Lockhart, T.E., Woldstad, J.C., Smith, J.L., 2003. Effects of age-related gait changes 340 on the biomechanics of slips and falls. Ergonomics 46, 1136-1160.

341 Manning, D.P., Shannon, H.S., 1981. Slipping accidents causing low-back pain in a 342 gearbox factory. Spine 6, 70-72.

343 Manning, D.P., Jones, C., 2001. The effect of roughness, floor polish, water, oil and 344 ice on underfoot friction: current safety footwear solings are less slip resistant 345 than microcellular polyurethane. Applied Ergonomics 32, 185-196.

346 Mao, D.W., Li, J.X., Hong, Y., 2006. Plantar pressure distribution during tai chi 347 exercise. Archives of Physical Medicine and Rehabilitation 87, 814-820.

348 Maynard, W.S., 2002. Tribology: Preventing slips and falls in the workplace. $349 \quad$ Occupational Health and Safety 71, 134-140.

350 Myung, R., Smith, J.L., 1997. The effect of load carrying and floor contaminants on $351 \quad$ slip and fall parameters. Ergonomics 40, 235-246.

352 Newton, R., Doan, B., Meese, M., Conroy, B., Black, K., Sebstianelli, W., Kramer, W., 353 2002. Interaction of wrestling shoe and competition surface: effects on 354 coefficient of friction with implications for injury. Sports Biomechanics 1, $355 \quad 157-166$.

356 Nurse, M.A., Nigg, B.M., 1999. Quantifying a relationship between tactile and 357 vibration sensitivity of the human foot with plantar pressure distributions 358 during gait. Clinical Biomechanics 14, 667-672.

359 Perkins, P.J., 1978. Measurement of slip between the shoe and ground during walking. 

Resistance, ASTM Special-Technical-Publication 649. American Society for Testing and Materials, Philadelphia, pp. 71-87.

363 Putti, A.B., Arnold, G.P., Cochrane, L., Abboud, R.J., 2007. The Pedar in-shoe system: 364 Repeatability and normal pressure values. Gait and Posture 25, 401-405.

365 Quesada, P., Rash, G., Jarboe, N., 1997. Assessment of Pedar and F-Scan revisited. $366 \quad$ Clinical Biomechanics 12, S15.

367 Redfern, M.S., Bidanda, B, 1994. Slip resistance of the shoe floor interface under 368 biomechanically-relevant conditions. Ergonomics 37, 511-524.

369 Redfern, M.S., Cham, R., Gielo-Perczak, K., Gronqvist, R., Hirvonen, M., 370 Lanshammar, H., Marpet, M., Pai, C.Y., Powers, C., 2001. Biomechanics of 371 slips. Ergonomics 44, 1138-1166.

372 Saari, J., 1990. On strategies and methods in company safety work: From 373 informational to motivational strategies. Journal of Occupational Accidents 12, 374

Tanaka, T., Noriyasu, S., Ino, S., Ifukube, T., Nakata, M., 1996. Objective method to determine the contribution of the great toe to standing balance and preliminary observations of age-related effects. IEEE Transactions on Rehabilitation 
Date: 29-10-2007

To: "Youlian Hong" youlianhong@cuhk.edu.hk

From: "Journal of Biomechanics" JBM@elsevier.com

Subject: BM-D-07-00298R1 - Editor Decision

Ref.: Ms. No. BM-D-07-00298R1

Prolonged toe grip and gentler heel strike are the strategies to adapt to slippery surface Journal of Biomechanics

Dear Dr. Hong,

Thank you for submitting your revised manuscript to the Journal of Biomechanics. Your manuscript has been reviewed by the original referees. I am pleased to inform you that your nice manuscript is acceptable, pending some minor revisions suggested by the reviewers to help clarify your study.

I therefore invite you to submit a revised manuscript, taking account of the reviewers' comments. If you choose to submit a revised manuscript, please provide a list of points of how you have responded to the reviewers' suggestions with the revised manuscript, at your earliest convenience.

To submit a revision, go to http://ees.elsevier.com/bm/ and $\log$ in as an Author. You will see a menu item called Submission Needing Revision. You will find your submission record there. Please update accordingly and submit your revised manuscript."

Please note:

* Any figures and tables should be included, even if these are unaltered.

* It is the author's responsibility to ensure that data presented in figures and tables agree with that provided in the text. Please cross check figures, tables and text carefully.

* Please double-check formatting of your references

* Please use your word processor to automatically number the lines of your manuscript and provide a word count from the Introduction through the Acknowledgments, including any Appendices.

Thank you again for submitting to the Journal of Biomechanics. I look forward to receiving your revised manuscript. 
Yours sincerely,

Farshid Guilak, Ph.D.

Editor-in-Chief

Reviewers' comments:

Reviewer \#1: No response

Reviewer \#2:

Summary and General Comments:

Overall, the authors did a good job answering the majority of the reviewers' questions.

The only issue remained unresolved is that the authors interpreted the increased normalized pressure-time integral (unit: $\mathrm{kPa}$ ) underneath the hallux and lateral toes area in the slippery oily condition, compared to the dry floor condition, as "prolonged" toe grip. In theory, when the pressure-time integral is normalized (or divided) by the stance time of the gait cycle, the resultant value should indicate the "average pressure" exerted over the investigated area during the whole stance time period. If the authors intended to investigate whether there was a prolonged hallux and toes contact, then the "contact time" of the pressure sensors in these areas should be analyzed. Therefore, it is suggested that the results be interpreted as "stronger toe grip" rather than "prolonged toe grip" while walking on a slippery surface without a fall.

>> We appreciate this comment, and would like to revise "prolonged toe grip" to "greater toe grip". The term "stronger toe grip" sounds like a sudden impulse of force exerted by the toe, or a higher ability of toe gripping force. The term "greater toe grip" better refers to a longer and larger exertion of toe grip. Therefore we would like to revise it to be "greater toe grip". We welcome suggestion from the editor.

Other Specific Suggestions:

Abstract:

Line 13: suggest changing "prolonged toe grip" to "stronger toe grip" 
>>> Revised accordingly.

Introduction:

Page 5, lines 12-14 of 1st paragraph: Gronqvist et al (2001) suggested "gentler toe landing" is one of the critical motor adaptations for safe gait while walking on slippery surface. This seems contradictory to the finding of the current study. Please address this issue in discussion.

>> In Gronqvist's study, some subjects landed with toes and therefore the authors concluded that gentler heel/toe landing is a strategy for safe gait. This is not contradictory to the findings of this study, since the greater toe grip happened after the landing until the next take off. In this study, all subjects landed with heel as instructed, and thus no toe-landing was observed. For simplicity, the toe landing described in Gronqvist's study is omitted in the revised manuscript.

Page 6, line 8: suggest changing "prolonged toe grip" to "stronger toe grip" >> Revised accordingly.

Methods:

Page 9, lines 16-17: 2nd paragraph: When the pressure-time integral is normalized (or divided) by the stance time of the gait cycle, the resultant value should indicate the "average pressure", not the total amount of pressure, exerted over the investigated area during the whole stance time period. And, it is important to note that the unit for the resultant value is pressure, not a time measure.

>> Revised accordingly.

Discussion:

Page 16, 2nd paragraph: Stronger toe grip may be a more appropriate interpretation unless the toe contact time was investigated and longer toe contract time was actually found in slippery condition in this study.

>> Revised accordingly. 


\section{ABSTRACT}

This study investigated the plantar pressure distribution during gait on wooden surface with different slipperiness in the presence of contaminants. Fifteen Chinese males performed ten walking trials on a 5-meter wooden walkway wearing cloth shoe in four contaminated conditions (dry, sand, water, oil). A pressure insole system was employed to record the plantar pressure data at $50 \mathrm{~Hz}$. Peak pressure and time-normalized pressure-time integral were evaluated in nine regions. In comparing walking on slippery to non-slippery surfaces, results showed a $30 \%$ increase of peak pressure beneath the hallux (from 195.6 to $254.1 \mathrm{kPa}$ ), with a dramatic $79 \%$ increase in the pressure time integral beneath the hallux (from 63.8 to $114.3 \mathrm{kPa}$ ) and a $34 \%$ increase beneath the lateral toes (from 35.1 to $47.2 \mathrm{kPa}$ ). In addition, the peak pressure beneath the medial and lateral heel showed significant $20-24 \%$ reductions respectively (from $233.6-253.5$ to $204.0-219.0 \mathrm{kPa}$ ). These findings suggested that greater toe grip and gentler heel strike are the strategies to adapt to slippery surface. Such strategies plantarflexed the ankle and the metatarsals to achieve a flat foot contact with the ground, especially at heel strike, in order to shift the ground reaction force to a more vertical direction. As the vertical ground reaction force component increased, the available ground friction increased and the floor became less slippery. Therefore, human could walk without slip on slippery surfaces with greater toe grip 
and gentler heel strike as adaptation strategies. 
Figure legends

Figure 1-A theoretical framework for the understanding of gait adaptation to prevent slip.

Figure 2 - The nine regions for evaluating the pressure distribution data in this study.

Figure 3 - Walking speed of the trials in the four conditions with different contaminants.

Figure 4- The changes in peak pressure and time-normalized pressure-time integral when walking on slippery conditions (oily condition). 


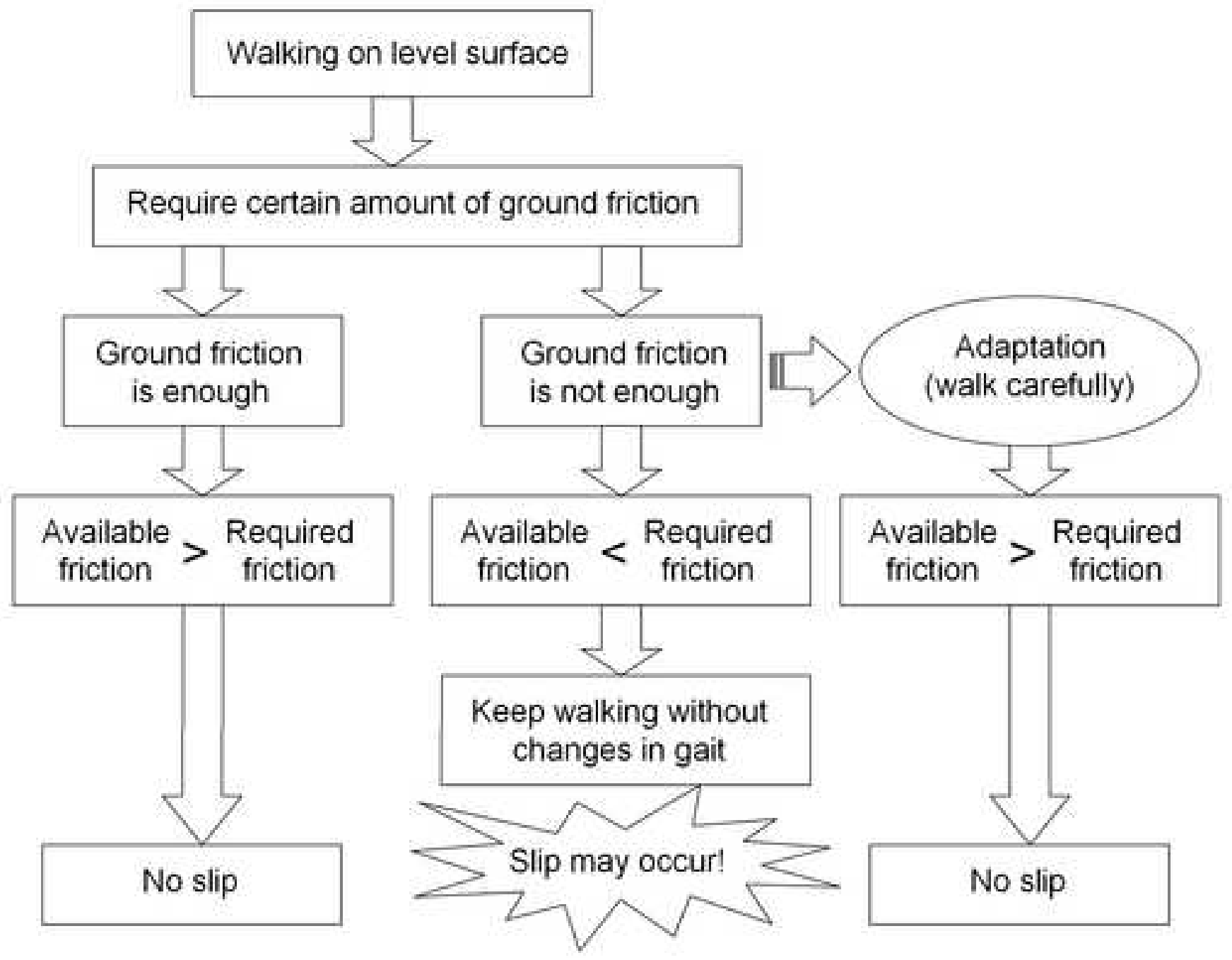


Figure(2)

Click here to download high resolution image






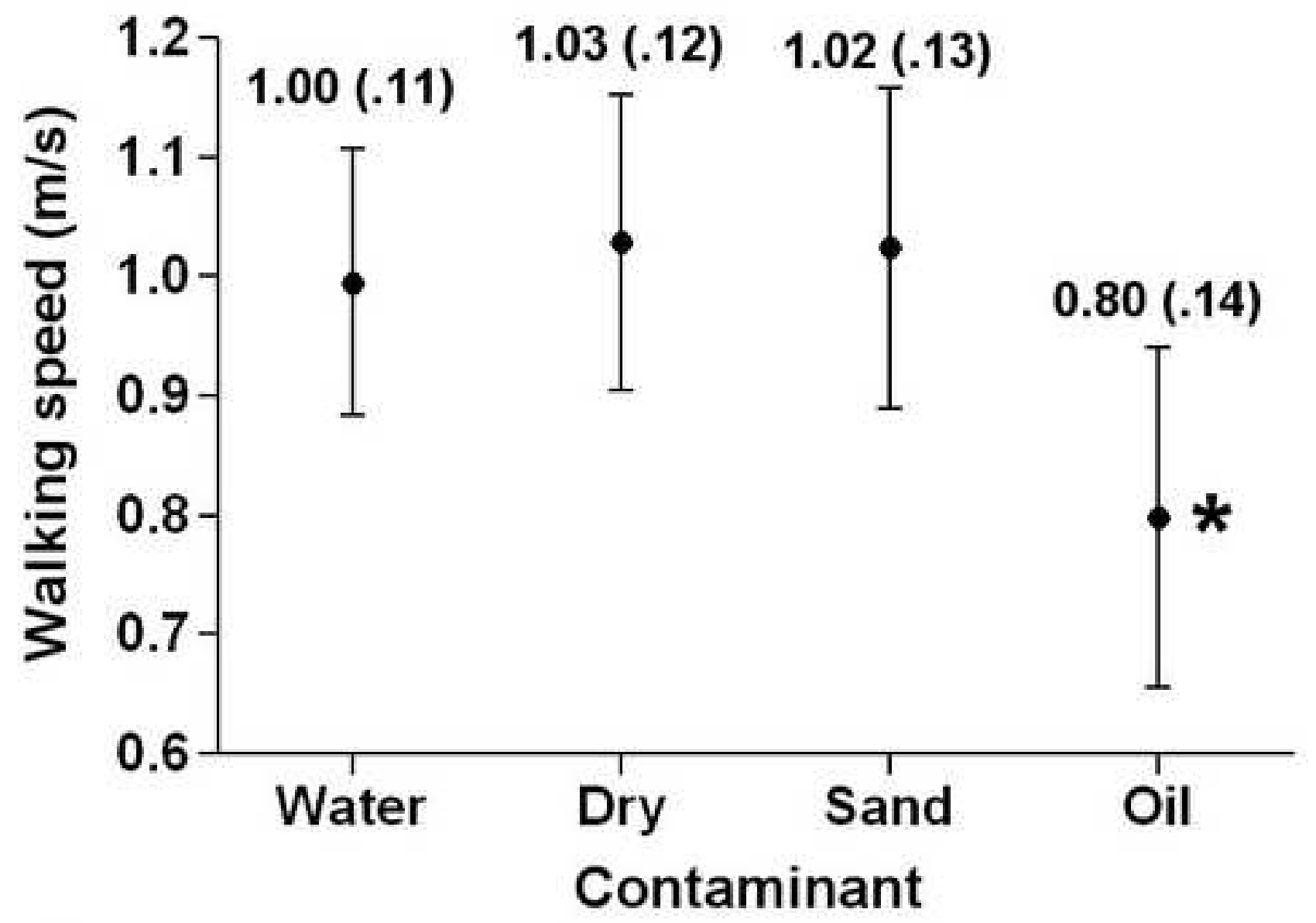

$*=$ significant difference from all other three contaminants $(p<0.05)$ 
Figure(4)
Click here to download high resolution image
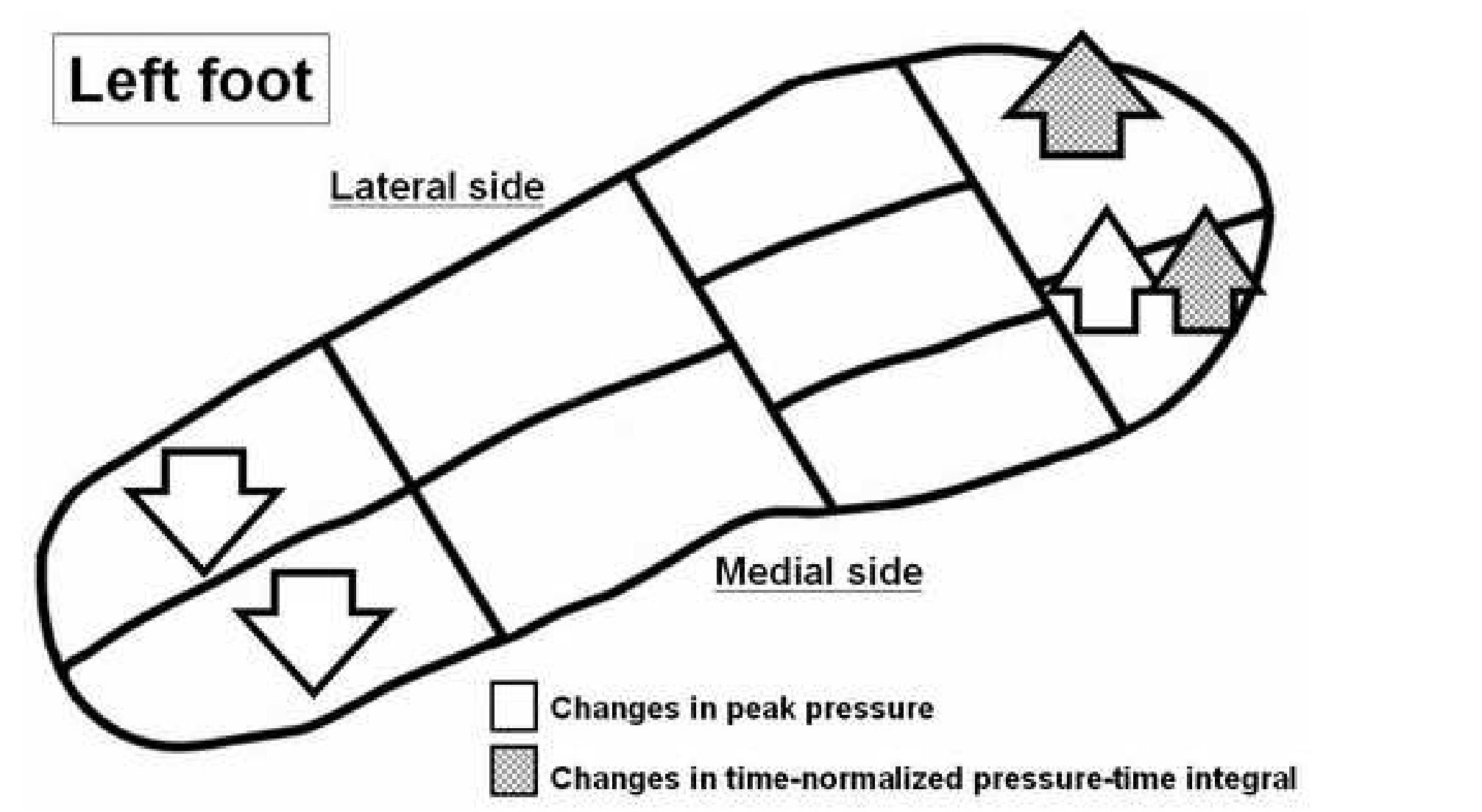
Table 1 - Dynamic coefficient of friction and slip resistant classification of wooden surface with different contaminants in this study

\begin{tabular}{lll}
\hline Contaminant & Dynamic coefficient of friction (DCOF) & Slip resistant class (From Gronqvist's scale, 1989) \\
\hline Water & $1.057(.056)$ & Very slip-resistant \\
Dry & $.808(.034)$ & Very slip-resistant \\
Sand & $.286(.021)$ & Slip-resistant \\
Oil & $.107(.006)$ & Slippery \\
\hline
\end{tabular}


Table 2 - Peak pressure $(\mathrm{kPa})$ of the nine regions when walking on different contaminated conditions (in increasing slipperiness order).

\begin{tabular}{llllll}
\hline & \multicolumn{5}{c}{ Peak pressure $(\mathrm{kPa})$} \\
& Water & Dry & Sand & Oil & ${\text { Statistical analysis p-value } / \text { Tukey }^{\mathrm{b}}}^{\mathrm{a}}$ \\
\hline Hallux & $179.9(48.6)$ & $195.6(36.6)$ & $181.2(44.5)$ & $254.1(63.2)$ & $<0.05 /(\mathrm{W}<\mathrm{O})^{*},(\mathrm{~S}<\mathrm{O})^{*}$ \\
Lateral toes & $110.9(29.4)$ & $113.3(23.4)$ & $105.4(21.5)$ & $120.7(17.7)$ & No significant difference \\
$1^{\text {st }}$ metatarsal head & $205.6(45.6)$ & $176.3(15.4)$ & $199.1(41.9)$ & $174.6(47.7)$ & No significant difference \\
$2^{\text {nd }}$ and $3^{\text {rd }}$ metatarsal heads & $228.6(41.1)$ & $206.0(24.4)$ & $220.6(33.3)$ & $183.6(49.8)$ & No significant difference \\
$4^{\text {th }}$ and $5^{\text {th }}$ metatarsal heads & $206.4(24.7)$ & $194.8(36.6)$ & $192.9(26.5)$ & $162.3(41.4)$ & No significant difference \\
Medial mid-foot $^{2}$ & $35.2(17.9)$ & $33.3(18.5)$ & $24.6(17.5)$ & $29.0(20.5)$ & No significant difference \\
Lateral mid-foot & $71.7(24.1)$ & $77.4(22.1)$ & $58.1(25.1)$ & $57.7(19.4)$ & No significant difference \\
Medial heel & $275.1(33.8)$ & $243.2(13.9)$ & $250.4(27.4)$ & $219.0(41.9)$ & $<0.05 /(\mathrm{W}>\mathrm{D})^{*},(\mathrm{~W}>\mathrm{O})^{*}$, \\
Lateral heel & $267.6(38.8)$ & $233.6(14.0)$ & $246.4(28.1)$ & $204.0(45.1)$ & $<0.05 /(\mathrm{W}>\mathrm{D})^{*},(\mathrm{~W}>\mathrm{O})^{*}$, \\
Total & $279.2(35.6)$ & $253.5(22.6)$ & $258.5(31.9)$ & $282.1(43.4)$ & No significant difference \\
\hline
\end{tabular}

Contaminants: W - Water, D - Dry, S - Sand, O - Oil

${ }^{a}$ ANCOVA test (walking speed as covariant) of the four conditions.

${ }^{\mathrm{b}}$ Results of Tukey test showed significant difference between groups $-{ }^{*} \mathrm{p}<.05$. 
Table 3 - Time-normalized pressure-time integral $(\mathrm{kPa})$ of the nine regions when walking on different contaminated conditions (in increasing slipperiness order).

\begin{tabular}{|c|c|c|c|c|c|}
\hline \multicolumn{6}{|c|}{ Time-normalized pressure-time integral $(\mathrm{kPa})$} \\
\hline & Water & Dry & Sand & Oil & Statistical analysis $p$-value ${ }^{\mathrm{a}} /$ Tukey $^{\mathrm{b}}$ \\
\hline Hallux & $48.1(10.3)$ & $63.8(15.3)$ & $65.3(26.1)$ & $114.3(25.0)$ & $<0.05 /(\mathrm{W}<\mathrm{O})^{*},(\mathrm{D}<\mathrm{O})^{*},(\mathrm{~S}<\mathrm{O})^{*}$ \\
\hline Lateral toes & $29.1(8.7)$ & $35.1(9.1)$ & $31.2(8.9)$ & $47.2(8.1)$ & $<0.05 /(\mathrm{W}<\mathrm{O})^{*},(\mathrm{D}<\mathrm{O})^{*},(\mathrm{~S}<\mathrm{O})^{*}$ \\
\hline $1^{\text {st }}$ metatarsal head & $84.6(27.6)$ & $81.5(18.4)$ & $92.6(25.6)$ & $92.5(32.6)$ & No significant difference \\
\hline $2^{\text {nd }}$ and $3^{\text {rd }}$ metatarsal heads & $100.3(30.0)$ & $96.5(20.9)$ & $104.6(20.8)$ & $97.7(34.8)$ & No significant difference \\
\hline $4^{\text {th }}$ and $5^{\text {th }}$ metatarsal heads & $94.0(21.7)$ & $93.2(24.1)$ & $93.1(13.3)$ & $85.5(27.4)$ & No significant difference \\
\hline Medial mid-foot & $10.6(6.9)$ & $11.2(8.2)$ & $8.4(7.2)$ & $8.6(7.4)$ & No significant difference \\
\hline Lateral mid-foot & $29.8(10.0)$ & $35.8(9.8)$ & $27.3(12.2)$ & $24.1(8.7)$ & No significant difference \\
\hline Medial heel & $88.6(31.4)$ & $80.9(20.6)$ & $99.7(21.7)$ & $76.6(29.4)$ & No significant difference \\
\hline Lateral heel & $86.7(31.4)$ & $75.9(19.7)$ & $96.4(21.1)$ & $71.2(30.0)$ & No significant difference \\
\hline Total & $167.4(37.4)$ & $161.4(25.8)$ & $176.2(28.2)$ & $180.8(31.6)$ & No significant difference \\
\hline
\end{tabular}

Contaminants: W - Water, D - Dry, S - Sand, O - Oil

${ }^{a}$ ANOVA test of the four conditions.

${ }^{\mathrm{b}}$ Results of Tukey test showed significant difference between groups $-{ }^{*} \mathrm{p}<.05$. 